\title{
Analysis of vegetation spatial distribution characteristics in Northwest China's arid desert area
}

\author{
Mingxin Wang*, and Yiping Zhao \\ Institute Of Water Resources for Pastoral Area, Ministry of Water Resources, Hohhot, China
}

\begin{abstract}
It is of great significance to study the characteristics of vegetation distribution in desert area for restoring vegetation, stabilizing ecosystem and ecological restoration in mining area. Taking the small watershed in Northwest China's arid desert area where the typical open-pit coal mine is located as the study area, using GF-2 (Gaofen-2 satellite) images, calculating the NDVI (Normalized Difference Vegetation Index) results of the study area, extracting NDVI $>0$ as the vegetation cover area and combing with DEM (Digital Elevation Model), we analyse the relationship between vegetation distribution and slope aspect and water flow path. We conclude that in the natural state, the proportion of vegetation distribution on semi-sunny slope and shady slope in the study area is $74.8 \%$, the proportion of sunny slope in the total area of the study area is $33.1 \%$, and the proportion of vegetation distribution on this slope is only $11.9 \%$, indicating that semi-sunny slope and shady slope are more suitable for growth in the study area. In the upper reaches of the basin, which is less affected by human activities, natural vegetation is distributed in strips along the flow path; In the mining area, which is obviously affected by human activities, the vegetation distribution characteristics change significantly with vegetation mainly distributed in the office area and being artificial greening.
\end{abstract}

Keywords: Vegetation spatial distribution characteristics; Northwest China's arid desert area; GF-2 image; Coal mining area.

\section{Introduction}

As the second largest energy in the world, coal plays an important role in China's energy supply. Located in the arid desert region of Northwest China, Wuhai City not only has a large-scale national coal base, but is also one of the key construction areas of the "Belt and Road" Initiative. Wuhai City is located in the arid desert area of Northwest China, with sparse rainfall, heavy wind and sand, vegetation degradation, serious land desertification problems, and extremely fragile ecological environment ${ }^{[1]}$. As the scale of coal mining continues to expand and the intensity of coal mining continues to increase in Wuhai City, the ecological and environmental problems there have become increasingly

\footnotetext{
* Corresponding author:wmx605@163.com
} 
serious $^{[2]}$. Under the specific geographical environment, the vegetation in this area gradually adapts to the environment of arid desert area through natural selection and forms a specific spatial distribution pattern. Studying the spatial vegetation distribution pattern under coal mining activities in this area has important scientific guiding significance for maintaining the regional ecological balance and restoring the ecological environment.

The GF-2 remote sensing satellite, independently developed by China, is the first civilian optical remote sensing satellite with a spatial resolution better than $1 \mathrm{~m}$. It has the characteristics of high spatial resolution, high radiation accuracy, high positioning accuracy and is currently widely used in national land resource surveys, soil moisture content monitoring and ecological environment monitoring, etc ${ }^{[3-5]}$. GF-2 satellite can give full play to the advantages of high-resolution image application, with high image definition, high geometric accuracy and rich spectral information, reaching or exceeding the level of remote sensing data with the same or close resolution at home and abroad ${ }^{[6]}$.

Using GF-2 image and DEM data, combined with field investigation, this paper analyzes the spatial distribution characteristics of vegetation of the small watershed in the typical desert area, including mining area. This paper considers the relationship between topography and confluence path of river system and vegetation distribution. The results are of great significance for guiding vegetation restoration and stabilizing ecosystem in mining areas.

\section{Overview of the study area}

The research selected a complete small watershed unit where a typical open-pit coal mine in the eastern part of Wuhai is located, and its geographic location is shown in Figure 1. The topography of the study area is high in the east and low in the west. The precipitation there is small and the evaporation is strong with an average annual precipitation less than $160 \mathrm{~mm}$ and average evaporation more than $3000 \mathrm{~mm}$. The study area belongs to a typical continental climate, with a short spring and autumn, long winter and summer, large temperature difference between day and night and long sunshine hours. The area between upper reaches of the river basin and the mining area is rocky mountains. whose main lithology is limestone The downstream is the Quaternary loose layer, which is mainly composed of gravel, sand, clay and aeolian sand.

The typical open-pit mining area is located in the middle and lower reaches of the basin. The north side of the mining area is open pit, the middle part is coal preparation area, and the south side is office area, as shown in Figure 1.

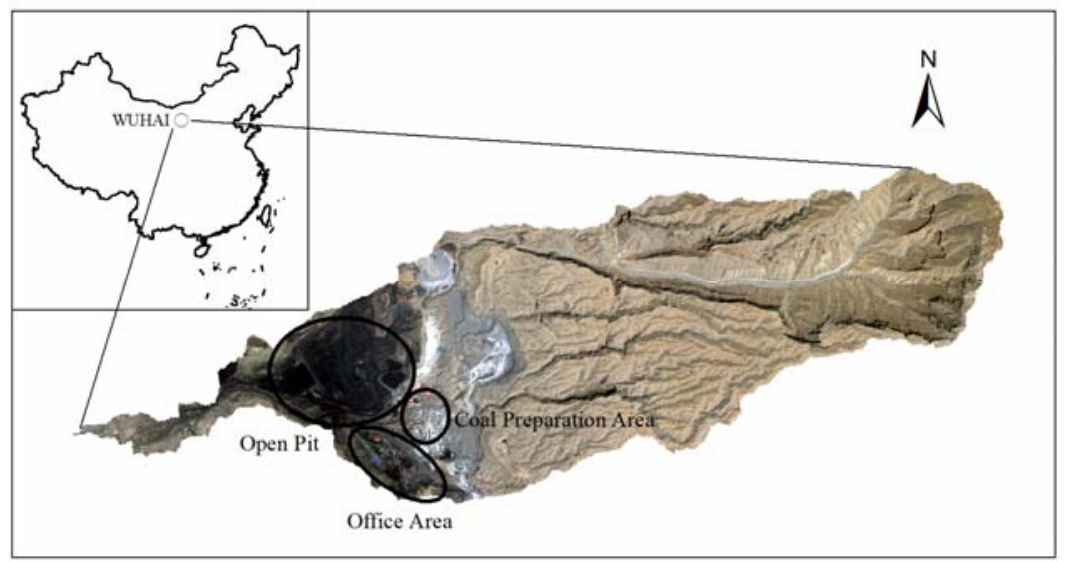

Fig. 1. Location of the study area. 


\section{Materials and methods}

\subsection{Research data}

GF-2 remote sensing data was used as the data source, and the observation date was June 26, 2016. It included one panchromatic image with $1 \mathrm{~m}$ spatial resolution and 4 multispectral images with $4 \mathrm{~m}$ spatial resolution. DEM data comes from ALOS satellite (Advanced Land Observing Satellite), with an accuracy of 12.5 meters. The above image data has a high resolution, which is helpful to improve the accuracy of the results.

\subsection{Research method}

After preprocessing GF-2 data, we calculated NDVI and extracted those larger than zero as vegetation distribution area. Then we used DEM for slope aspect analysis, with shade slope: $0 \sim 45^{\circ}$ and $315^{\circ} \sim 360^{\circ}$, half shade slope: $45^{\circ} \sim 135^{\circ}$, sunny slope: $135^{\circ} \sim 225^{\circ}$, half sunny slope: $225^{\circ} \sim 315^{\circ}$, and the flat area without a downslope direction assigned a value of -1 and classified as flat slope. We then calculated the area proportion of vegetation distribution in different slopes to analyse each slope's suitability for vegetation growth. Using the hydrological analysis tool, we extracted the flow path and basin boundary. We analyzed the relationship between vegetation distribution and confluence path of river system. The specific process is shown in Figure 2.

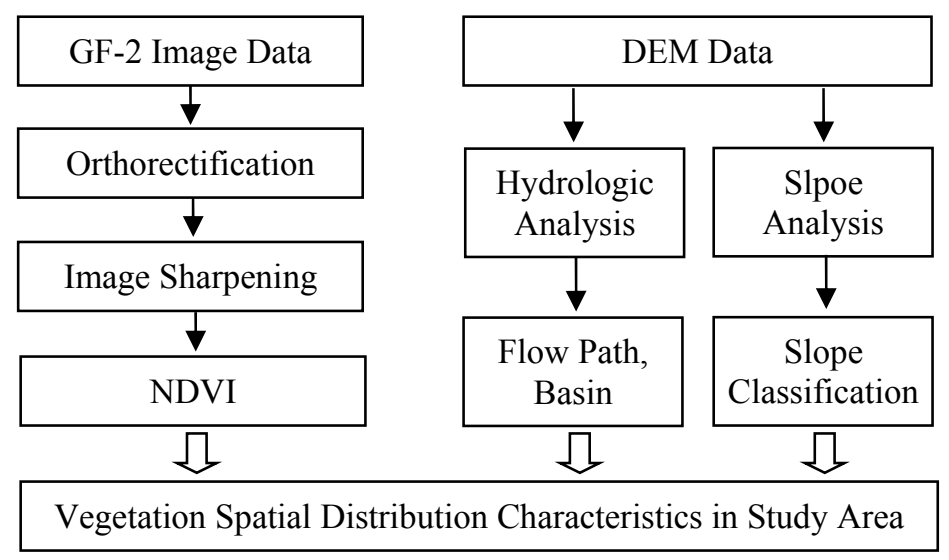

Fig. 2. Vegetation distribution research process.

\section{Results and analysis}

\subsection{Relationship between vegetation distribution and slope aspect}

The results of comprehensive vegetation distribution and slope aspect analysis are shown in Figure 3 which demonstrates a patchy distribution of the vegetation in the basin. Different grayscale is used to represent the slope direction, with white colour represents the sunny slope and dark gray represents the shady slope. According to Figure 3, vegetation is mainly distributed on semi-sunny slope and shady slope. The results of slope aspect classification area ratio are shown in Figure 4. The proportion of vegetation distribution, classified by slope aspect, is shown in Figure 5. 


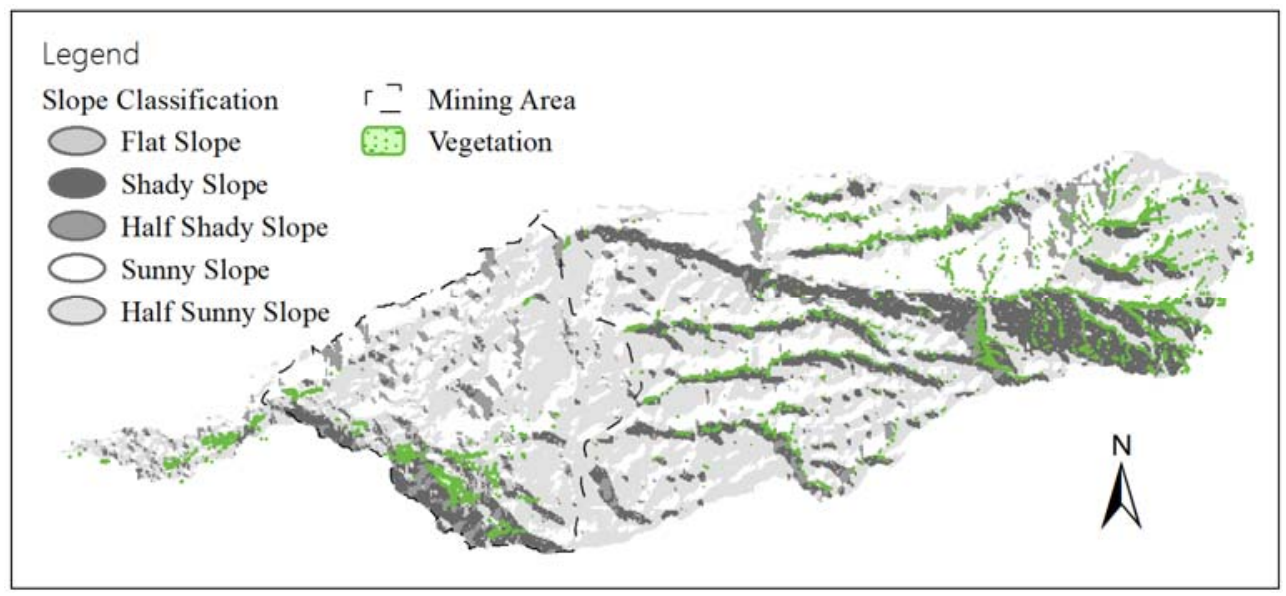

Fig. 3. Results of vegetation distribution and aspect classification.

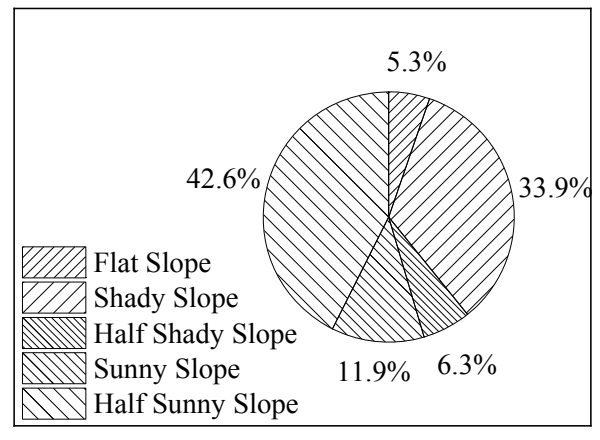

Fig. 4. Watershed slope classification and area ratio.

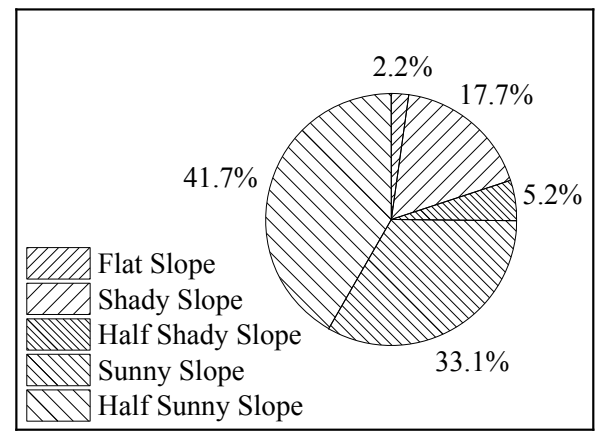

Fig. 5. The proportion of vegetation distribution classified by slope aspect.

The comparison of slope aspect classification and vegetation distribution is summed in Table 1 . The proportion of sunny slope is $33.1 \%$, while the proportion of vegetation on this slope is only $11.9 \%$, with a difference of $-21.2 \%$; the proportion of shady slope is $17.7 \%$, while the proportion of vegetation on shady slope is $33.9 \%$, with a difference is $16.2 \%$. The above shows that vegetation in the arid desert area of the Northwest China is more suitable to grow on shady slopes than on sunny slopes.

Table 1. Comparison of slope aspect classification and vegetation distribution.

\begin{tabular}{|c|c|c|c|}
\hline Slope Classification & Basin(\%) & Vegetation(\%) & Difference(\%) \\
\hline Flat Slope & 2.2 & 5.3 & 3.0 \\
\hline Shady Slope & 17.7 & 33.9 & 16.2 \\
\hline Half Shady Slope & 5.2 & 6.3 & 1.1 \\
\hline Sunny Slope & 33.1 & 11.9 & -21.2 \\
\hline Half Sunny Slope & 41.7 & 42.6 & 0.9 \\
\hline
\end{tabular}

\subsection{Analysis of the relationship between vegetation distribution and flow path}

The comprehensive results of vegetation distribution and hydrological analysis show that vegetation in the upper reaches of the basin is distributed in strips along the flow path, as 
are shown in Figure 6. In the mining area, the distribution characteristics of vegetation exhibit a significant change. Because of the impact of human activities, the vegetation, maily artifical greening, is distributed mainly in the office area.

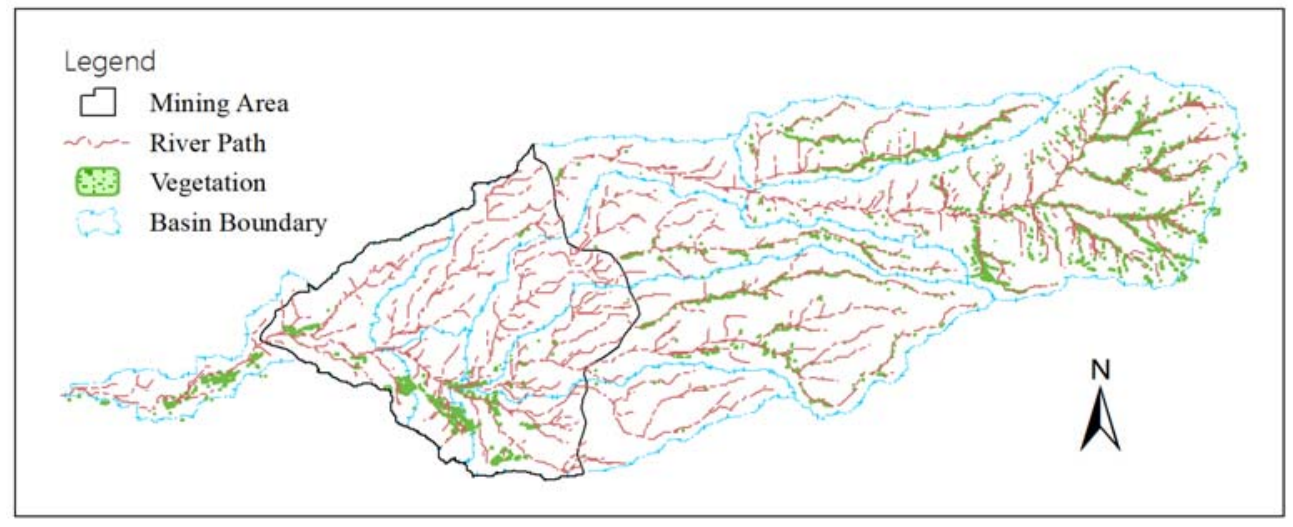

Fig. 6. Vegetation distribution and water flow path results.

\section{Discuss}

Due to the low rainfall in the arid desert area, the sparse vegetation distribution and the harsh environment, GF-2 images, having the advantages of high resolution, can accurately and conveniently extract the vegetation in the arid desert area, which is of great significance for the study of the vegetation distribution in the arid desert area. The vegetation in the study area is distributed in strips, which is consistent with the field survey results. The analysis of the relationship between vegetation and slope distribution and flow path in the watershed reveals that the natural vegetation is generally distributed in strips along the water flow path, and is more suitable to grow on half sunny slopes and shade slopes.

The origin of patchy vegetation is still a controversial subject for many scholars. In arid desert areas, precipitation is scarce and mostly heavy rain, which forms runoff and erodes the ground. The soil continues to accumulate along the path of water flow, providing suitable soil and moisture for vegetation growth. The solar radiation of half sunny slope and shady slope is relatively lower, which is beneficial to reduce water evaporation. The results are consistent with the theory of the origin of patchy vegetation in arid area.

\section{Conclusion}

Based on the usage of GF-2 remote sensing image and the analysis of the spatial distribution characteristics of vegetation in typical watershed of coal mining area in arid desert area of Northwest China, the following conclusions can be drawn:

Vegetation in the study area is mainly distributed on semi-sunny slope and shady slope, accounting for $74.8 \%$ of the area. The sunny slope accounts for $33.1 \%$ of the total area of the study area, while the vegetation distribution on this slope is only $11.9 \%$. The proportion of shady slope in the basin is $17.7 \%$, and the proportion of vegetation distributed on shady slope is $33.9 \%$. It indicates that vegetation is more suitable to grow on semi-sunny slope and shady slope in its natural state. From the confluence path of the river system and the location of vegetation distribution in the study area, the vegetation distribution in the upper reaches of the basin is distributed in strips along the water flow path. However, within the mining area, the distribution characteristics of vegetation have changed significantly, which is obviously affected by human activities. Vegetation is mainly distributed in the office area, 
which is artificial greening. The above conclusions can be used to guide the restoration of mining vegetation in arid desert steppe area of Northwest China.

\section{Acknowledgements}

This research was supported by the National Key R\&D Program of China "Eco-security technology for coal mining bases in the Northwestern arid desert regions in China" (2017YFC0504400) — "Studies on the key technologies of water resources protection and comprehensive utilization in mining area" (2017YFC0504405).

\section{References}

1. L.M. Rong, C.L. Zhang, Y. Wang, T.N. Zhao, Inner Mongolia Forestry, 04 (2018)

2. T.N. Zhao, Y.X. Zhang, B. Cao, H.J. Xiao, C.L. Zhang, S.Y. Zhao, X.P. Guo, Journal of Soil and Water Conservation, 32 (2018)

3. Z.H. An, C.M. Wu, X.Y. Sun, Y. Yang, Y.J. Wang, Spacecraft Recovery \& Remote Sensing, 38(2017)

4. X.M. Mai, Z.Q. Hu, Y.L. Zhao, Journal of China Coal Society, 44(2019)

5. J.N. Cai, T.H. He, M.Z. Huang, Environmental Monitoring and Forewarning, 10(2018)

6. T. Peng, H. Guan, W. He, Spacecraft Recovery \& Remote Sensing, 36(2015) 